\title{
Memória, democracia e educação: reflexões sobre diversidade étnica e história oral*
}

\author{
Amilcar Araujo Pereira**
}

Em pleno século XXI ainda podemos observar vários aspectos da democracia brasileira que se encontram bastante incompletos. Se as desigualdades sociais - embora tenham diminuído nos anos recentes - ainda são uma marca de nossa sociedade, o racismo continua sendo um elemento estruturante dessas desigualdades e definidor de maiores ou menores oportunidades para brasileiros, dependendo de seu pertencimento étnico-racial (pretos, pardos, indígenas, brancos ou amarelos), como afirmam diversos pesquisadores. Dados estatísticos e análises sobre as desigualdades raciais na área da educação, no mercado de trabalho, na área da saúde etc. têm demonstrado há décadas a permanência desse elemento nada democrático em nossa sociedade: o racismo (Paixão; Carvano, 2008; Henriques, 2001; Hasenbalg, 1979; Fernandes, 1965; entre outros). Essa permanência, que se reflete em discriminações não somente em relação às pessoas, mas, também aos próprios conteúdos curriculares selecionados para serem trabalhados, dificulta muito a construção de uma educação democrática de fato para todos os brasileiros.

* Uma primeira versão deste artigo foi apresentada durante o XI Encontro Nacional de História Oral na mesa-redonda História oral e diversidade étnica, em julho de 2012, na Universidade Federal do Rio de Janeiro. Agradeço a Verena Alberti pela constante e profícua interlocução.

** Doutor em História pela Universidade Federal Fluminense (UFF), com estágio doutoral na Johns Hopkins University, nos Estados Unidos, é professor de Ensino de História na Universidade Federal do Rio de Janeiro (UFRJ). 
O caráter eurocêntrico presente historicamente nos currículos de história e de outras disciplinas escolares no Brasil ainda é evidente.

O objetivo deste artigo é propor reflexões sobre a importância do trabalho com a diversidade étnica no ensino de história e das demais disciplinas - um trabalho que lide com memórias e referenciais culturais diversos, construindo espaços de enunciação das diferenças, e que seja pautado pelos princípios da pluralidade cultural e do respeito a essas diferenças (Bhabha, 2003). Através da utilização da metodologia da história oral e de outras estratégias e possibilidades educacionais, esse tipo de trabalho pode contribuir muito para a democratização dos espaços escolares e, quem sabe, até mesmo para o combate ao racismo no Brasil.

Como já dizia Florestan Fernandes desde a década de 1960, o brasileiro "tem preconceito de ter preconceito" e, nesse sentido, teria "dois níveis diferentes de percepção da realidade e de ação ligados com a 'cor' e a 'raça': primeiro o nível manifesto, em que a igualdade racial e a democracia racial se presumem e proclamam; segundo, o nível disfarçado, em que funções colaterais agem através, abaixo e além da estratificação social" (Fernandes, 1972/2007, p. 82). Embora se afirme recorrentemente no "nível manifesto" que vivemos num país sem conflitos raciais e com iguais oportunidades para todos, através das percepções e ações no "nível disfarçado", como já apontava Fernandes em meados do século $\mathrm{XX}$, as desigualdades raciais se perpetuam em nossa sociedade. Um exemplo interessante da permanência desse tipo de percepção e ação pode ser observado em duas pesquisas, uma realizada na USP em 1988 e outra realizada em todo o Brasil pelo Instituto Datafolha em 1995, ambas citadas no livro da antropóloga Lilia Moritz Schwarcz intitulado Racismo no Brasil (2001). Na primeira pesquisa, em 1988, quando perguntados, $97 \%$ dos entrevistados respoderam que não eram racistas; entretanto, $98 \%$ dos mesmos entrevistados responderam também que conheciam pessoas racistas! $\mathrm{Ou}$ seja, quase todos os entrevistados conheciam pessoas racistas, mas praticamente nenhum deles afirmava ser racista. Na segunda pesquisa, a de 1995 , realizada em todo o Brasil, o resultado foi bastante semelhante, pois apenas $10 \%$ dos entrevistados declararam ser racistas, enquanto $89 \%$ afirmaram a existência de racismo no Brasil (Schwarcz, 2001, p. 11, 76).

Essa realidade em que os preconceitos e ações discriminatórias, mesmo quando não explicitados, alimentam as desigualdades sociais e raciais, também se reproduz nas escolas de todo o Brasil. A pesquisa realizada em 2009 pela FIPE (Fundação Instituto de Pesquisas Econômicas) a pedido do INEP 
(Instituto Nacional de Estudos e Pesquisas Educacionais Anísio Teixeira) em 501 escolas públicas de todo o país, baseada em mais de 18,5 mil entrevistas com alunos, pais e mães, diretores, professores e funcionários, revelou que 99,3\% das pessoas no ambiente escolar demonstram algum tipo de preconceito étnico-racial, socioeconômico, com relação a portadores de necessidades especiais, gênero, geração, orientação sexual ou territorial. Entre estas, de acordo com os dados da pesquisa, 94,2\% têm preconceito étnico-racial (Pesquisa indica..., 2009).

Os impactos desses preconceitos e discriminações na formação de nossas crianças e jovens, e de nossa sociedade como um todo, são muitos. Como diz o ditado popular, "é preciso conhecer para respeitar". Nesse sentido, a questão das memórias construídas nas escolas ganha relevância, tendo em vista que, em geral, os grupos discriminados não têm, ou raramente têm, suas memórias e histórias trabalhadas nos espaços escolares. Vale ressaltar que vários autores já afirmaram a importância da memória para a construção identitária. Essa discussão ganha ainda mais relevância se concordarmos com Michael Pollak, quando ele afirma: "Podemos dizer que a memória é um elemento constituinte do sentimento de identidade, tanto individual como coletiva, na medida em que ela é também um fator extremamente importante do sentimento de continuidade e de coerência de uma pessoa ou de um grupo em sua reconstrução de si” (Pollak, 1992, p. 204). Jacques Le Goff também tratou do tema - reforçando a afirmação anterior, mas acrescentando em sua reflexão a relação entre a memória, a identidade e a ação dos homens e mulheres na sociedade em que vivem - quando afirmou, por exemplo, que: "A memória, onde cresce a história, que por sua vez a alimenta, procura salvar o passado para servir o presente e o futuro". Ainda segundo o autor: "A memória é um elemento essencial do que se costuma chamar identidade, individual ou coletiva, cuja busca é uma das atividades fundamentais dos indivíduos e das sociedades de hoje, na febre e na angústia” (Le Goff, 1984, p. 46).

A relação entre memória e identidade torna-se evidente também nas falas das lideranças do movimento negro entrevistadas em todas as regióes do país, entre setembro de 2003 e abril de 2007, para o projeto História do movimento negro no Brasil: constituição de acervo de entrevistas de história oral. Esse projeto foi implementado pela Dra. Verena Alberti e por mim no Centro de Pesquisa e Documentação de História Contemporânea do Brasil (CPDOC) da Fundação Getulio Vargas (FGV). Realizamos 38 entrevistas de história 
oral com lideranças do movimento negro de todas as regiões do Brasil, ${ }^{1}$ e percebemos em muitos casos a necessidade dos militantes de investir nos espaços de educação, questionando a "história oficial" ou a "memória oficial" sobre a abolição da escravidão e mesmo sobre a participação da população negra na história do Brasil. A "reavaliação do papel do negro na história do Brasil", por exemplo, é uma demanda que já aparecia na Carta de Princípios do Movimento Negro Unificado, elaborada em 1978.

Embora desde os anos 1980 exista uma grande produção historiográfica sobre o período da escravidão no Brasil, ainda se estuda muito pouco nas escolas brasileiras a "agência" da população negra durante aquele período, e menos ainda sobre a participação da população negra na formação de nossa sociedade a partir do pós-abolição. Personagens históricos como Luiz Gama ${ }^{2}$ ou Maria Firmina dos Reis, ${ }^{3}$ ou mesmo organizações como a Frente Negra Brasileira (FNB) ou o já citado Movimento Negro Unificado (MNU), ${ }^{4}$ somente para citar alguns poucos exemplos, ainda são pouquíssimo conhecidos por professores e alunos de história.

Memórias e histórias sobre as lutas e sobre a participação da população negra na constituição de nossa sociedade estiveram ausentes dos espaços escolares historicamente, o que significa um problema para a construção da democracia no Brasil no que diz respeito à formação educacional dos seus cidadãos. A pluralidade étnico-racial, refletida em memórias e histórias diversas presentes nos currículos e nas práticas educativas, é importante para todos os brasileiros, tanto negros quanto brancos, amarelos ou indígenas. As relações são sempre dialógicas. Ao mesmo tempo em que a ausência de memórias e

1 A pesquisa contou com o apoio do South-South Exchange Programme for Research on the History of Development (Sephis), sediado na Holanda, do CNPq e da FAPERJ.

2 Luiz Gama (1830-1882) nasceu em Salvador, Bahia, e é considerado por muitos historiadores como um dos maiores abolicionistas brasileiros. Embora tenha nascido livre, por ser filho de uma escrava forra, foi vendido como escravo pelo pai aos 10 anos de idade. Na juventude aprendeu a ler e tomou ciência de sua condição de homem livre. Autodidata, tornou-se rábula, um advogado sem formação universitária, e atuou nos tribunais em São Paulo, onde conseguiu libertar mais de 500 pessoas escravizadas. Foi também jornalista e fundador do Partido Republicano Paulista. Ver Santos (2010).

3 Maria Firmina dos Reis (1825-1917) nasceu em São Luís do Maranhão. Autodidata, foi professora, musicista, compôs o Hino à libertação dos escravos, colaborou com poesias em vários jornais e, em 1859, publicou o livro Úrsula, que pode ser considerado o primeiro romance abolicionista brasileiro e um dos primeiros de autoria feminina no Brasil. Em 1880, Maria Firmina dos Reis fundou a primeira escola mista do Maranhão. Ver Mendes (2006).

4 Sobre essas e outras organizações do movimento negro criadas no século XX, ver Pereira (2013). 
histórias de determinado grupo nas escolas dificulta as construções identitárias positivas pelos indivíduos desse grupo, a presença hegemônica de memórias e histórias de um grupo específico pode suscitar a construção de identidades que alimentem um sentimento de superioridade em relação aos outros grupos sub-representados nos currículos. Tanto sentimentos de inferioridade quanto de superioridade atrapalham a construção de uma perspectiva democrática ao longo do processo formativo. Construir espaços de enunciação das diferenças nos currículos e nas escolas pode contribuir para se "soltar o homem", como dizia Frantz Fanon, psiquiatra negro, ao analisar na década de 1950 os impactos psicológicos do colonialismo sobre negros e brancos:

Para nós, aquele que adora os pretos é tão 'doente' como aquele que os abomina. Inversamente, o Negro que quer embranquecer a sua raça é tão infeliz como aquele que prega o ódio ao Branco. Em termos absolutos, o Negro não é mais digno de estima que o Checo, e na realidade trata-se de soltar o homem. (Fanon, 1975, p. 37).

\section{As Leis 10.639/2003 e 11.645/2008}

Levando em consideração a discussão acima, como Ana Maria Monteiro e eu afirmamos em outra oportunidade, a abordagem e o trabalho qualificado com os conteúdos curriculares relacionados à história e cultura da África, dos africanos, dos afrodescendentes e dos indígenas no Brasil, nos termos das Leis 10.639/2003 e 11.645/2008, tem merecido amplo destaque em escolas e cursos de formação de professores de história. (Pereira; Monteiro, 2012, p. 10) A primeira lei, a 10.639, de maneira emblemática, foi sancionada pelo presidente Luiz Inácio Lula da Silva logo após a posse na Presidência da República, em 9 de janeiro de 2003. Ao introduzir a obrigatoriedade do ensino de história e culturas africanas e afro-brasileiras nas escolas, essa lei atendeu a demandas históricas do movimento negro brasileiro "pela reavaliação do papel do negro na história do Brasil" e "pela valorização da cultura negra” (Pereira, 2012). Da mesma forma, após pressão dos movimentos indígenas, o mesmo presidente, cinco anos depois, sancionou a Lei 11.645 em 10 de março de 2008, acrescentando à lei anterior a obrigatoriedade do ensino de história e culturas indígenas. Ambas as leis alteraram o Artigo 26-A da Lei 9.394, de 20 de dezembro de 1996, a conhecida Lei de 
Diretrizes e Bases da Educação Nacional (LDB). A determinação expressa na nossa $\mathrm{LDB}$, alterada pelas leis citadas, veio para saldar a dívida dos currículos das escolas brasileiras em relação ao direito de grande contingente da população ter suas histórias incluídas e, consequentemente, conhecidas e estudadas com respeito e reconhecimento por todos os cidadãos de nosso país. Mais do que isso, essas leis nos induzem a efetivamente buscar superar a tantas vezes denunciada "perspectiva eurocêntrica", que permanece como orientação reprodutora de concepções colonialistas e que, mesmo com as muitas lutas e mudanças já realizadas, ainda temos dificuldades em ultrapassar. O racismo existente no Brasil, como se viu acima, alimenta-se também dos preconceitos e da ignorância em relação às outras culturas e etnias formadoras de nossa sociedade. Mas é importante ressaltar que não se trata de apenas trocar uma perspectiva eurocêntrica por outra, com outro "centro". Ao contrário, incluir novos conteúdos relacionados aos temas das histórias e culturas dos africanos, afrodescendentes e indígenas nos obriga a realizar novos estudos e pesquisas e a pensar alternativas que implicam necessariamente a redefinição e a reorganização da história ensinada em sua seleção de conteúdos curriculares e processos de didatização (Pereira; Monteiro, 2012, p. 11).

As ações dos movimentos negros e a participação da população negra na história do Brasil, em sua complexidade, por exemplo, são pouco conhecidas nas escolas, em grande medida, em função da ainda pequena quantidade de pesquisas realizadas sobre a "história e cultura afro-brasileira e africana" de que fala a Lei 10.639/2003. O sociólogo Paul Gilroy, ao indicar o impacto causado pelos "movimentos negros no Brasil e de suas histórias de luta", afirma que eles "recentemente conseguiram forçar o reconhecimento do racismo como um aspecto estruturante da sociedade brasileira, uma conquista que é ainda mais notável porque ocorreu em meio a celebrações oficiais" (Gilroy, 2001 , p. 9). De fato, até o ano de 1995, os representantes do Estado brasileiro sempre apresentavam o Brasil, em todos os fóruns internacionais, como uma verdadeira "democracia racial", um país onde não haveria conflitos e problemas relacionados à questão racial. Foi em junho de 1996, durante o seminário internacional Multiculturalismo e racismo: o papel da ação afirmativa nos Estados democráticos contemporâneos, organizado pelo Departamento dos Direitos Humanos da Secretaria dos Direitos da Cidadania do Ministério da Justiça, que o então presidente da República Fernando Henrique Cardoso reconheceu a existência de discriminação racial no Brasil e refletiu sobre a 
necessidade de se "inventar", também em âmbito governamental, novas possibilidades de combate às discriminações.

Compreender a formação de nossa sociedade como uma construção plural, na qual todas as matrizes culturais e étnico-raciais foram e são igualmente importantes, ao mesmo tempo em que compreendemos as diversas culturas como advindas de processos históricos, é fundamental para o ensino de história em um país que se quer democrático de fato. Hebe Mattos afirma que "a história se apresenta como disciplina-chave" para se desenvolver um trabalho em que, ao invés de "reforçar culturas e identidades de origem, resistentes à mudança, mais ou menos 'puras' ou 'autênticas", se busque "educar para a compreensão e o respeito à dinâmica histórica das identidades socioculturais efetivamente constituídas" (Mattos, 2003, p. 129). E, para que isso seja possível, é preciso que as histórias da África, dos africanos e as histórias das populações negras e indígenas no Brasil, em toda a sua complexidade, sejam pesquisadas e trabalhadas por professores e alunos nas salas de aula de história.

\section{História oral e diversidade étnica}

As leis citadas acima, quando implementadas com seriedade e qualidade - no que diz respeito também aos conteúdos curriculares e às práticas educativas -, têm o potencial de transformar o ensino de história e de outras disciplinas no Brasil, na medida em que nos levem a inserir a diversidade étnico-racial no processo educacional. Nesse sentido, a polifonia proporcionada pela metodologia da história oral se mostra bastante adequada, sempre que articulada com a questão da diversidade étnico-racial no ensino. As diferentes vozes e visões expressadas nas entrevistas podem servir de fontes para a construção de reflexões e para a ampliação de conhecimentos históricos acerca de vários temas importantes tanto para a história do Brasil quanto de outros países. Um interessante exemplo nesse sentido é a entrevista concedida pelo militante negro José Correia Leite (1900-1989) no início da década de 1980

5 José Correia Leite e Jayme de Aguiar fundaram, em 1924, o jornal Clarim d'Alvorada, um dos jornais da chamada imprensa negra paulista do início do século XX. Correia Leite também foi um dos fundadores da Frente Negra Brasileira, em 1931, mas desligou-se da agremiação ainda no momento da aprovação do estatuto, por divergir de sua inclinação ideológica. Fundou então o Clube Negro de Cultura Social, em 1932. Participou da Associação do Negro Brasileiro, fundada em 1945. Em 1956 fundou em São Paulo, com outros militantes, a Associação Cultural do Negro (ACN) e, em 1960, participou da fundação da revista Niger. 
para Luiz Silva (mais conhecido pelo nome artístico CUTI), e publicada no livro ...E disse o velho militante José Correia Leite (Leite; CUTI, 1992). No trecho citado abaixo, Correia Leite, sobre a agitação no meio negro em São Paulo no contexto da Revolução de 1930, disse o seguinte:

1929 tinha sido o ano de uma recessão muito grande e as consequências na situação do negro foram graves. [...] Então, o movimento político fez a gente ir esmorecendo a idéia da realização do Congresso [da Mocidade Negra naquele ano]. O Getulio perdeu as eleições e veio a Revolução de 1930. Aí foi uma fase que a gente pode distinguir o movimento negro antes de 1930 e depois de 1930. Este tomou outra feição. O negro, por intuição ou qualquer coisa, na Praça da Sé se reunia em grupos e as discussões eram calorosas. Estava sempre à frente o Isaltino Veiga dos Santos, o que mais agitava os grupos. Foi um sujeito que lutou muito. Sem ele não teria existido a Frente Negra Brasileira. Em 1930 não se tinha a idéia do nome, mas estava-se discutindo de como o negro poderia participar. Não se queria ficar marginalizado na transformação que se esperava. Havia um contentamento de ver aquelas famílias de escravagistas apeadas do poder. Era claro que na transformação tudo ia mudar. O negro sentia isso. (Leite; CUTI (Luiz Silva), 1992, p. 91; grifo meu).

Correia Leite apresentou, em um pequeno trecho de entrevista, uma outra possibilidade de se pensar sobre esse processo histórico que recebeu influência direta de acontecimentos internacionais, como a crise de 1929 nos Estados Unidos, e que resultou, entre outras coisas, na criação da Frente Negra Brasileira em 1931, a maior organização do movimento negro no Brasil do século XX. Existem muitos outros depoimentos sobre esse período da história do Brasil registrados em livros - como o Frente Negra Brasileira: depoimentos, organizado por Márcio Barbosa (1998) -, que podem enriquecer, a partir do contato com diversas perspectivas, por exemplo, os estudos sobre a chamada "Era Vargas" (1930-1945), que é um conteúdo presente tanto nos currículos de história do ensino fundamental quanto do ensino médio.

Outro bom exemplo nesse sentido pode ser observado no trecho da entrevista de Amauri Mendes Pereira, liderança do movimento negro no Rio de Janeiro desde a década de 1970, concedida a Verena Alberti e a mim, no âmbito do projeto por nós implementado no CPDOC/FGV, citado acima, 
quando ele fala sobre o impacto da Lei dos $2 / 3$ para a população negra no início da década de 1930:

Meu avô que me ensinou sobre a Lei dos $2 / 3$ do tempo do Getulio, que obrigava toda empresa a contratar $2 / 3$ de brasileiros, e que eu tenho usado muito, porque essa foi a primeira lei de cotas no Brasil: $2 / 3$ dos postos de trabalho para brasileiros, que, na época, ele dizia, eram pretos. Preto que não tinha direito ao trabalho. Os trabalhos estavam nas mãos dos portugueses, espanhóis, italianos. No Rio de Janeiro, eram os portugueses, e ele dizia: 'Quando veio a Lei dos 2/3, o Batista Luzardo chamava a gente, estavam construindo a rua Larga, e dizia: 'Vai, Pereira, pega sua turma e vai trabalhar. Entra na obra, trabalha na força, pega e vai fazendo o que você achar que tem que fazer. No final do dia, o cara tem que te pagar. Se o português não te pagar, você pega ele e traz para cá. Traz até amarrado, mas não bate não. O cara tem que pagar”. Para fazer vingar a lei. O Batista Luzardo ficava ali onde hoje é a Central do Brasil, ali era a chefatura de polícia. Ele era o chefe de polícia. Em 1931, 32, meu avô já estava no Rio, já tinha sido um dos fundadores do sindicato da construção civil. (Alberti; Pereira, 2007, p. 38).

A Lei dos 2/3 é pouco conhecida atualmente, embora tenha sido objeto de grande polêmica logo no início do governo de Getulio Vargas, com repercussão na imprensa escrita do Rio de Janeiro e de São Paulo na época. Levando-se em consideração o impacto das políticas imigratórias implementadas pelos sucessivos governos desde o final do século XIX, que trouxeram milhões de imigrantes europeus para ocuparem os postos de trabalho disponíveis naquele momento, o trecho citado acima pode proporcionar reflexões sobre o processo histórico ao acrescentar a perspectiva de setores da população negra nos debates e nas disputas sociais e políticas existentes naquele período.

Ao entrevistarmos lideranças do movimento negro brasileiro no contexto de um projeto de pesquisa, Verena Alberti e eu buscamos estabelecer um quadro com as principais estratégias e formas de articulação, com as diferentes influências, enfim, com os elementos que possibilitaram e/ou incentivaram a constituição desse movimento nas diversas regiões do país. A história do movimento negro faz parte da história do Brasil, assim como as histórias dos movimentos indígenas e de outros movimentos políticos e identitários. 
Segundo Verena Alberti, a história oral seria a metodologia ideal para esse tipo de projeto de pesquisa, pois

[ela] é especialmente indicada para o estudo da história política, entendida não só como história dos 'grandes homens' e 'grandes feitos', e sim como estudo das diferentes formas de articulação de atores e grupos, trazendo à luz a importância das ações dos indivíduos e de suas estratégias. Através de entrevistas de história oral, é possível reconstituir redes de relação, formas de socialização e canais de ingresso na carreira, bem como investigar estilos políticos específicos a indivíduos e grupos. (Alberti, 2004b, p. 24-25).

Pensando também em relação às entrevistas, o documento de história oral produzido por entrevistador(a) e entrevistado(a), a autora, em outro texto, prossegue demarcando as características dessa metodologia:

A entrevista de história oral permite também recuperar aquilo que não encontramos em documentos de outra natureza: acontecimentos pouco esclarecidos ou nunca evocados, experiências pessoais, impressões particulares etc. [...] Mas acreditamos que a principal característica do documento de história oral não consiste no ineditismo de alguma informação, tampouco no preenchimento de lacunas de que se ressentem os arquivos de documentos escritos ou iconográficos, por exemplo. Sua peculiaridade - e a da história oral como um todo - decorre de toda uma postura com relação à história e às configurações socioculturais, que privilegia a recuperação do vivido conforme concebido por quem viveu. (Alberti, 2004a, p. 22-23).

Em relação à especificidade da história oral, a autora complementa, ressaltando a importância da subjetividade e das representações construídas pelos entrevistados, que nos informam a respeito do passado: "Sua grande riqueza está em ser um terreno propício para o estudo da subjetividade e das representaçôes do passado tomados como dados objetivos, capazes de incidir (de agir, portanto) sobre a realidade e sobre o nosso entendimento do passado" (Alberti, 2004b, p. 42; grifo no original). Entrevistas como as que Verena Alberti e eu fizemos no âmbito do projeto citado acima, com lideranças do movimento negro das décadas de 1970 e 1980, são muito ricas e nos colocam em contato com experiências de pessoas autoidentificadas como negras, com suas subjetividades e representações do passado, além de suas 
leituras de mundo e perspectivas distintas - que podem contribuir para a compreensão da complexidade da história do Brasil, por exemplo. Ao mesmo tempo, questões sensíveis como as relações étnico-racias nas escolas podem ser abordadas em salas de aula a partir de reflexóes sobre trechos de entrevistas como o que segue abaixo, em que Zélia Amador, liderança do movimento negro em Belém do Pará desde a década de 1980, fala sobre sua experiência em relação à questão racial na escola:

Eu estava na terceira série primária e devia ter nove anos. Eu tinha um bom relacionamento na turma, porque era considerada inteligente porque sabia matemática. Aí chegou uma pessoa na sala, pediu para interromper a aula e perguntou quem da sala queria participar de uma dança. Aí eu fiquei louca, claro que eu queria participar daquela coisa! A freira disse: 'Quem quiser, levanta.' Eu levantei. A freira mesmo, professora, foi escolhendo todo mundo e não me escolheu. Como não me escolheu, eu fiquei na sala; as outras que foram escolhidas saíram. E fiquei grilada: 'Por que eu não fui?.' Quando acabou a aula, fui perguntar para ela por que ela não me chamou. Ela ficou relutante em dizer, mas eu insisti. Até que não teve jeito - uma moleca daquelas chatas, perguntando, perguntando, perguntando!... Como não teve jeito, ela disse assim: 'Porque para essas apresentações, a gente procura umas crianças mais ajeitadinhas, mais bonitinhas'. Aí eu pensei: 'Bom, tem alguma coisa'. Porque eu, em absoluto, me achava feia. E comecei a me comparar com as pessoas que ela tinha escolhido. Nunca me esqueço que disse: 'Mas ela chamou a Benedita!'. A Benedita era branca, mas eu achava a Benedita tão feia, com uma cara de cavalo!... Depois eu fui entender: porque, do grupo que levantou, eu era a de fenótipo marcadamente negro. Essa foi a minha primeira experiência, digamos assim, que vai marcar essa questão. Daí para a frente você começa a sacar as coisas. (Alberti; Pereira, 2007, p. 42-43).

A problematização de uma estética de matriz europeia, inclusive em relação aos fenótipos, como elemento determinante do que seria "belo", poderia render interessantes discussões sobre as relações raciais no Brasil a partir da utilização de trechos de entrevistas como o reproduzido acima. Outro exemplo que poderia ser utilizado para discutir em sala de aula a questão das relações étnico-raciais em nosso país está no extrato da entrevista com o mesmo Amauri Mendes Pereira, quando ele fala sobre sua experiência em relação à questão racial na escola: 
Quem tinha preocupação com o problema racial era minha avó materna, Maria Trindade. Ela foi escrava. Nasceu em 1872, um ano depois da Lei do Ventre Livre, mas só foi saber que existia essa lei na Abolição. ${ }^{6}$ Ela vivia sempre como escrava da família. Ela tinha uma consciência racial aguda! Sempre falava: 'Meu filho, mesmo você sendo mais clarinho, um dia você vai saber o que é isso'. E aí aconteceu. Na quarta série, o último ano do primário, era assim: de cada série, um aluno que se destacava ia compor a guarda de honra da bandeira. E o aluno que se destacasse mais na escola seguraria a bandeira. Tinha o porta-bandeira da escola e um guarda-bandeira de cada série. Acho que o segundo lugar fazia a saudação. Era uma forma de prestigiar os melhores alunos. Então eu batalhei nos dois primeiros meses, março e abril, para ter a nota, porque em maio sempre tinha a solenidade da Abolição, alguém lia Castro Alves. ${ }^{7}$ Eu queria fazer uma homenagem para minha avó, que foi escrava. Eu queria que minha avó fosse ver. E aí tirei a melhor nota em abril. A melhor nota da escola! Pensei: 'Vou segurar a bandeira!'

$\mathrm{Na}$ véspera do evento, a diretora me chamou e disse alguma coisa assim: 'O Roberto vai segurar a bandeira'. O Roberto era um outro menino, a gente disputava na mesma turma: eu, Roberto, Zé Romualdo e Celeste, que era a única menina que chegava junto. Tínhamos as maiores notas desde os anos anteriores. O Roberto era branco. Ele ia segurar a bandeira porque vinha uma autoridade, e a diretora disse: 'Você entende, não é, meu filho?'. Eu saí correndo da escola, subi o morro desesperado, dizendo: 'Vovó, aconteceu!'. Essas coisas de criança; depois foi fazer sentido para mim. Ficou claro que eu não ia poder segurar a bandeira, porque o Roberto é que precisava ir, e isso ficou associado à cor da pele. Tanto que eu saí correndo, fui para o morro e falei para a minha avó. Ela me botou no colo e começou a falar: 'Meu filho, não tem jeito não, é assim mesmo. [...] Estou orgulhosa assim mesmo'. (Alberti; Pereira, 2007, p. 37-38).

6 A Lei 2.040 de 28 de setembro de 1871, conhecida como Lei do Ventre Livre, concedeu liberdade aos filhos de escravas nascidos a partir de sua promulgação. Os senhores de suas mães tinham obrigação de criá-los até a idade de oito anos, após o que poderiam utilizar-se dos seus serviços até completarem 21 anos, ou entregá-los ao Estado mediante o recebimento de indenização de $600 \$ 000$ (seiscentos mil réis). A Abolição ocorreu em 13 de maio de 1888, quando a princesa imperial regente, Isabel de Bragança, sancionou a Lei 3.353, que havia sido decretada pela Assembleia Geral do Império, declarando extinta a escravidão no Brasil. Ver Brasil (1888).

7 Antônio Frederico de Castro Alves (1847-1871) faleceu aos 24 anos, vítima de tuberculose, deixando inacabado o poema Os escravos, uma série de poesias em torno do tema da escravidão, entre as quais se destaca $O$ navio negreiro (1868). Ficou conhecido como "o poeta dos escravos". Ver Castro Alves (s.d.). 
Como se constituíram as identidades políticas e culturais e as relações étnico-raciais nos espaços que abrigavam as escolas citadas, em lugares tão distantes entre si quanto Belém do Pará e Rio de Janeiro? Hebe Mattos propõe a separação, do ponto de vista teórico, entre as noções de "cultura" e "identidade". Segundo a autora, as identidades individuais e coletivas devem ser vistas como construções culturais, por isso históricas e relacionais, e que "dependem, em cada caso, das formas históricas em que as fronteiras entre nós e os outros se constroem, se reproduzem ou se modificam" (Mattos, 2003, p. 128; grifo meu). Nesse sentido, devemos pensar a cultura como processo, no qual tradições e práticas culturais circulam, transformam-se e modificam-se. Acredito que seja muito importante a compreensão das histórias de construção das identidades étnico-raciais para que possamos tentar lidar com o racismo em toda sua complexidade.

A metodologia da história oral também pode ser utilizada para a realização de trabalhos com alunos de escolas em seus próprios bairros, por meio de pesquisas orientadas pelos professores com o objetivo de tentar compreender, através da realização e análise das entrevistas de história oral com pais, avós, bisavós, vizinhos mais velhos, lideranças comunitárias, políticas, religiosas etc., como foram os processos históricos nos quais se constituíram as manifestações culturais, as organizações políticas ou as identidades étnico-raciais encontradas em seu próprio bairro. Esse tipo de trabalho, que articularia a metodologia da história oral com a história local, teria grande potencial no sentido de contribuir para o ensino de história, na medida em que o processo de construção de conhecimento teria como "protagonistas" os próprios alunos, orientados pelos professores que fariam a "mediação didática" ao coordenar e acompanhar as pesquisas realizadas pelos alunos.

Para tanto, os professores poderiam iniciar o trabalho através da montagem de um projeto de pesquisa sobre a história da comunidade ou bairro que abriga a escola, identificando, através das trocas de ideias e consultas feitas com os alunos, as possíveis manifestações culturais ou organizações locais que seriam o "objeto" da pesquisa a ser realizada. Ao identificar o objeto da pesquisa, os professores poderiam então, em seguida, indicar aos alunos a leitura de textos de livros ou revistas que apresentassem informações e reflexões sobre esse objeto. Por exemplo, caso se tratasse de uma organização do movimento negro ou um terreiro de candomblé existente no local, seria importantíssimo que os alunos fizessem leituras mais amplas sobre movimento negro ou sobre culturas afro-brasileiras, mesmo que em livros didáticos ou paradidáticos 
encontrados nas escolas, antes de iniciarem a pesquisa de campo. O terceiro passo a ser dado pelo professor, após as leituras e discussóes sobre o tema do objeto da pesquisa, poderia ser a elaboração, junto com os alunos, de um roteiro de entrevistas. Esse roteiro, que necessariamente precisaria incorporar informações e questões surgidas ao longo da pesquisa e das leituras, é um elemento fundamental para o sucesso da atividade como um todo.

O quarto passo seria a gravação das entrevistas com as lideranças das organizações pesquisadas - ou mesmo com pais, avós, vizinhos dos alunos -, que poderia ser feita com telefones celulares ou mesmo com pequenos gravadores digitais facilmente encontrados em lojas de todo o Brasil. Por fim, essas gravações poderiam ser discutidas em sala de aula, dando início a muitas outras possibilidades de trabalhos sobre a temática pesquisada, inclusive com o professor realizando a "mediação didática" ao fazer articulações entre os resultados da pesquisa e os aspectos da história do Brasil e do mundo que surgissem ao longo da realização e das avaliações dos trabalhos de pesquisa. $\mathrm{O}$ interesse pelas histórias de sua própria comunidade ou bairro, bem como sua participação direta no processo de pesquisa, inclusive realizando as entrevistas de história oral, poderia facilitar o engajamento dos alunos nesse tipo de trabalho de ensino de história.

Ao contemplar e lidar com a diversidade étnico-racial presente nas escolas e nas regióes que as abrigam, trabalhos como esse estariam de acordo com as sugestões presentes nas Diretrizes curriculares nacionais para a educação das relaçôes étnico-raciais e para o ensino de história e cultura afro-brasileira e africana, aprovadas pelo Conselho Nacional de Educação e publicadas pelo Ministério da Educação ainda em outubro de 2004, e teriam também o potencial de contribuir para a democratização dos processos educativos em nosso país.

\section{Referências}

ALBERTI, Verena. Manual de história oral. 2. ed. Rio de Janeiro: Editora FGV, $2004 a$. Ouvir contar: textos em história oral. Rio de Janeiro: Editora FGV, $2004 \mathrm{~b}$.

ALBERTI, Verena; PEREIRA, Amilcar Araujo (Org.). Histórias do movimento negro no Brasil. Rio de Janeiro: Pallas; CPDOC/FGV, 2007.

BARBOSA, Márcio. Frente Negra Brasileira: depoimentos. São Paulo: Quilombhoje, 1998. 
BHABHA, Homi. O local da cultura. Belo Horizonte: Editora da UFMG, 2003.

BRASIL. Lei no 3.353 , de 13 de maio de 1888 . Declara extinta a escravidão no Brasil. Disponível em: <http://legis.senado.gov.br/legislacao/ListaPublicacoes.action?id=10262 1\&tipoDocumento=LEI\&tipoTexto=PUB $>$. Acesso em: 25 jul. 2007.

CASTRO ALVES: biografia. In: ACADEMIA BRASILEIRA DE LETRAS. [s.d.]. Disponível em: <http://www.academia.org.br/abl/cgi/cgilua.exe/sys/start.htm?infoid= 828\&sid=124>. Acesso em: 26 jul. 2007.

FANON, Frantz. Pele negra, máscaras brancas. Porto: Paisagem, 1975.

FERNANDES, Florestan. A integração do negro à sociedade de classes. São Paulo: Editora Nacional, 1965.

. O negro no mundo dos brancos. 2. ed. rev. São Paulo: Global, 1972/2007.

GILROY, Paul. O Atlantico negro: modernidade e dupla consciência. São Paulo: Editora 34; Rio de Janeiro: Universidade Cândido Mendes; Centro de Estudos Afro-Asiáticos, 2001.

HASENBALG, Carlos. Discriminação e desigualdades raciais no Brasil. Rio de Janeiro: Graal, 1979.

HENRIQUES, Ricardo. Desigualdade racial no Brasil: evolução das condições de vida na década de 90 - texto para discussão n 807. Rio de Janeiro: Ipea, 2001.

LE GOFF, Jacques. Memória. In: ENCICLOPÉDIA Einaudi. Lisboa: Imprensa NacionalCasa da Moeda, 1984. v. 1 (Memória-História).

LEITE, José Correia; CUTI (Luiz Silva). ...E disse o velho militante José Correia Leite: depoimentos e artigos. Organização e textos: CUTI (Luiz Silva). São Paulo: Secretaria Municipal de Cultura, 1992.

MATTOS, Hebe. O ensino de história e a luta contra a discriminação racial no Brasil. In: ABREU, Martha; SOIHET, Rachel (Org.). Ensino de história: conceitos, temáticas e metodologia. Rio de Janeiro: Casa da Palavra, 2003.

MENDES, Algemira Macêdo. Maria Firmina dos Reis e Amélia Beviláqua na história da literatura brasileira: representação, imagens e memórias nos séculos XIX e XX. 282 p. Tese (Doutorado em Letras) - PUCRS, Porto Alegre, RS, 2006.

PAIXÃO, Marcelo; CARVANO, Luiz M. (Org.). Relatório anual das desigualdades raciais no Brasil: 2007-2008. Rio de Janeiro: Garamond Universitária, 2008.

PEREIRA, Amilcar A. "O mundo negro": relações raciais e a constituição do movimento negro contemporâneo no Brasil. Rio de Janeiro: Pallas, 2013. 
. Por uma autêntica democracia racial!: os movimentos negros nas escolas e nos currículos de história. Revista História Hoje, Manaus, v. 1, n. 1, 2012. Disponível em: <http://rhhj.anpuh.org/ojs/index.php/RHHJ/article/view/21>. Acesso em: 31 jan. 2013.

PEREIRA, Amilcar A.; MONTEIRO, Ana Maria (Org.). Ensino de história e culturas afrobrasileiras e indígenas. Rio de Janeiro: Pallas, 2012.

PESQUISA indica que 99,3\% das pessoas no ambiente escolar são preconceituosas. Uol Educação, 17 jun. 2009. Disponível em: <http://educacao.uol.com.br/ultnot/2009/06/17/ ult105u8241.jhtm>. Acesso em: 7 jul. 2011.

POLLAK, Michael. Memória e identidade social. Estudos Históricos, Rio de Janeiro, v. 5, n. $10,1992$.

. Memória, esquecimento, silêncio. Estudos Históricos, Rio de Janeiro, v. 2, n. 3, 1989.

SANTOS, Luiz Carlos. Luiz Gama. São Paulo: Selo Negro, 2010.

SCHWARCZ, Lilia M. Racismo no Brasil. São Paulo: Publifolha, 2001.

Resumo: O objetivo deste artigo é propor reflexões sobre a importância do trabalho com a diversidade étnica no ensino de história e das demais disciplinas - um trabalho que lide com memórias e referenciais culturais diversos, construindo espaços de enunciação das diferenças, e que seja pautado pelos princípios da pluralidade cultural e do respeito a essas diferenças. Através da utilização da metodologia da história oral e de outras estratégias e possibilidades educacionais, esse tipo de trabalho pode contribuir muito para a democratização dos espaços escolares e, quem sabe, até mesmo para o combate ao racismo no Brasil.

Palavras-chave: diversidade étnica, história oral, democracia, Brasil.

\title{
Memory, democracy and education: reflections on ethnic diversity and oral history
}

\begin{abstract}
The aim of this paper is to propose reflections on the importance of working with ethnic diversity in the teaching of History and other disciplines - a work that deals with memories and many cultural references, constructing spaces to the enunciation of the differences, and being guided by the principles of cultural plurality and respect for these differences. By using the methodology of oral history and other educational strategies, such work can greatly contribute to the democratization of schools and perhaps even to combat racism in Brazil.
\end{abstract}

Keywords: ethnic diversity, oral history, democracy, Brazil.

Recebido em 03/02/2013

Aprovado em 15/04/2013 